\title{
FACTORS AFFECTING ADS VIEWS ON SOCIAL NETWORKS: HO CHI MINH CITY CASE STUDY
}

\author{
Tran Huu Ai \\ Mai Thi Hong Dao \\ Van Hien University, Ho Chi Minh City, Vietnam \\ Bui Vinh Thanh \\ Vietin Bank, Vietnam
}

Many people join social networks to interact with each other. The research shows that there are at least 3 key factors affecting the behavior of people who are viewing ads on social networks. The survey of 317 customers in Ho Chi Minh City has determined the following three groups of factors: (1) Attitudes towards ads on social networks (Relevance of advertising on social networks, Trust with social networks, Trust with an advertising brand); (2) Subjective standards while viewing ads on social networks; (3) The ability to control the perceived behavior while viewing ads on social networks.

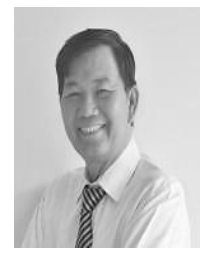

\section{Ai Tran Huu}

$\mathrm{PhD}$, lecturer of Faculty of Economics, Van Hien University, Ho Chi Minh City, Vietnam Research interests: markets of agricultural products, SMEs functioning and government support organic food markets, ecological economics, environmental issues of economic development and corporate social responsibility

Published more than 70 papers, active member of the editorial boards of International journals

E-mail: aith@vhu.edu.vn

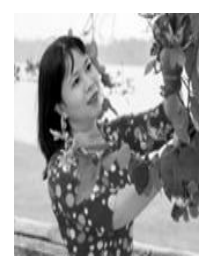

\section{Dao Mai Thi Hong}

MBA, Lecturer of Faculty of Economics, Van Hien University, Ho Chi Minh City, Vietnam

Research interests: SMEs functioning and government support, consumer behavior, innovative products markets and finances

Published more than 20 papers in International journals

E-mail: daomth@vhu.edu.vn

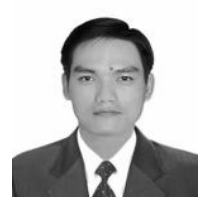

\section{Bui Vinh Thanh}

MBA Director Vietin Bank, Tay Tien Giang Branch, Vietnam

Research interests: SMEs functioning and government support, consumer behavior, innovative products markets and finances. Published more than 20 papers in International journals

E-mail: bvth@vhu.edu.vn 
Keywords: consumer behavior; social networks; online ads; Ho Chi Minh City; Vietnam

\section{Introduction}

According to the eMarketer report, by 2021 there will be over 3 bln social media users worldwide. In Vietnam, the Social Media Stats report said that in May 2019, 57.43\% of the local residents were using Facebook, 13\% were Twitter users, 12.81\% used YouTube, 10\% used Pinterest, $1.71 \%$ had personal accounts on Instagram.

It is generally expected that the number of social network users in Vietnam will continue to increase in the coming years. With the increasing number of the Internet users and the social networks' visitors in Vietnam, advertising in this online environment is promising success for many related businesses.

Each country and nation has its own rules and beliefs. Therefore, to develop on a global scale, a social network must have its own filters, which can vary flexibly, depending on a legal system of a particular country. Therefore, social networks need a unique philosophy. Instead of simply following the rules of the social network owner, these platforms should make sure "the game belongs to the user", and then the user will be the true owner of the social network, its co-owner, along with the initial founder.

Within today's digital economy, social networks will not be able to compete with other digital platforms if they are being operated individually, single handedly. To be successful, social networks need to have a support ecosystem. In our particular case in question this would be the ecosystem of Vietnamese digital products.

Many empirical studies have already shown the relationship between attitudes and intentions in relation to social media ads viewed by the users. For example, Hsu et al. (2017) studied the perceptions, attitudes and behaviors of social media users in the context of Dubai Emirate.

More specifically, these authors studied how/whether users focus on advertising within social networks and whether/how they click on such ads to get more information. Their research results show that the attitude towards social advertising positively affects user behavior towards advertising on social networks. Similarly, the study of Chin et al. (2015) also investigated the relationship between attitudes to advertising on social networks and behavioral responses to advertising on social networks. Their research results also found a positive relationship between the attitudes towards social advertising and behavioral responses to social advertising.

However, there have also been some recent studies showing that attitudes may have a weak or even zero impact on the intention to see ads on social networks. Specifically, respondents in the study conducted by Ajzen (1991) argued that advertising on social networks was irrelevant to them or it was perceived as unreliable and therefore not viewed. This finding has been further confirmed in the study of Baker \& White (2010) university students are not interested in advertising because they perceive advertising to be unreliable.

Similarly, Chang \& Chang (2010) also pointed out that social network users do not view ads not because they dislike advertising on social networks, but simply because they do not pay attention to them while they are focused on other content such as the profile of friends, new photos and so on. 


\section{FACTORS AFFECTING ADS VIEWS ON SOCIAL}

Thus, such an inconsistency in the research results clearly shows there is a research gap. And for this very reason we would like to find out what conditions can change the relationship from attitude to intention to see ads on social networks.

\section{Literature Review}

Studies related to online advertising and social media are mainly based on such theories as the theory of reasoned action (TRA), the theory of planned behavior (TRB) and the technology acceptance model (TAM). Basing on the psychosocial research theories, Ajzen \& Fishbein (1980) developed the rational action theory (TRA) to predict and understand individuals' behavior.

The planned behavioral theory is an extension of the TRA theory by means of three factors: attitude towards behavior, awareness of social pressure or social influence on individual behavior, and the ability to control behavior.

The more favorable the subjective level and the ability to control behavior are, the stronger will be the intention to implement certain behavior (under consideration), according to the TRA theory. Davis (1993) developed their technology acceptance model to explain individual information system adoption behavior. This model assumes that the use of information systems is influenced by the intention to conduct certain behavior.

Ajzen \& Driver (1992) used an extended form of the TPB model to assess the factors influencing group purchasing behavior on the Internet. Lin et al. (2015) also used the combination of TPB and TAM theories in their unified model to predict the intentions of customers using Internet banking in Vietnam. Their study assessed two factors that affect the attitude towards using Internet banking: perceived usefulness and perceived ease of use of the Internet banking system.

Lin \& Kim (2016) research used the TPB model to explain the intention to see in-app ads among mobile device users in China. The survey results (480 young people using mobile devices) showed that trust in advertising in the application acts as a prerequisite factor affecting the attitude towards such advertising.

Soares \& Pinho (2014) used TAM and TRA models to study and assess students' intentions to use Facebook in Pakistani universities. The results of their study showed that there are no significant effects of the factors within the TAM and TRA models including perceived enjoyment, perceived ease of use, and the intent to use Facebook.

Social networks have already become an integral part of our daily life. Social networks are web-based services that allow individuals to (1) build profiles publicly or semi-publicly within a limited system, (2) articulate a list of other users sharing the connection with them, and (3) to view and browse through lists of their connections and those of others in the same network. In most general terms, social networks allow creation and strengthening of emotional relationships or cohesion among users.

Advertising is defined as any means of expressing and promoting paid ideas, goods, and services through an identified sponsor. In the research of Grabner-Kräuter (2009) advertising is defined as a form of providing paid information designed to persuade people to continue receiving information about current or future behavior. 
Table 1 - Summary of factors affecting consumers' intention to view social media ads in Ho Chi Minh City

(Source: made by co-authors)

\begin{tabular}{|c|c|c|}
\hline No. & Components of scale & Authors \\
\hline 1 & $\begin{array}{l}\text { Attitudes towards ads on social networks } \\
\text { - Trust with social networks } \\
\text { - Trust with brand ads on social networks } \\
\text { - Relevance of advertising on social networks }\end{array}$ & $\begin{array}{c}\text { Ajzen, 1991; } \\
\text { Fisbein \& Ajzen,1975 }\end{array}$ \\
\hline 2 & Subjective standards of seeing ads social networks & $\begin{array}{c}\text { Ajzen, 1991; } \\
\text { Gironda \& Korgaonkar, } 2014\end{array}$ \\
\hline 3 & $\begin{array}{l}\text { The ability to control the perceived behavior of } \\
\text { viewing ads on social networks }\end{array}$ & $\begin{array}{l}\text { Taylor \& Todd, 1995; Ajzen, 1991; } \\
\text { Gordinda \& Korgaonkar, } 2014\end{array}$ \\
\hline 4 & Intention of viewing ads on social networks & Chin et al., 2015; Fisbein \& Ajzen, 1975 \\
\hline 5 & Behavior of viewing ads on social networks & Ajzen \& Fishbein, 1980 \\
\hline
\end{tabular}

\section{Research Model and Hypotheses}

Intention to see ads on social networks and behavior of viewing ads on social networks

The intention to perform a behavior is commonly understood as "the degree of strength or weakness of a person's willingness to perform a specific act" (Ajzen, 1991). The research by Chin et al. (2015) demonstrated that the intention to hit the "Like" button on Facebook directly affects the actual behavior of customers when clicking the "Like" button on Facebook. So, our first hypothesis has been formulated as follows:

Hypothesis 1: Intention to see advertising on social networks is positively associated with the behavior of viewing ads on social networks of consumers in Ho Chi Minh City.

\section{Attitudes towards ads and the intention to see ads on social networks}

Attitude plays an important role in psychosocial research (Ajzen \& Fishbein, 1974). The attitude reflects favorable or unfavorable assessment of a person, the way he/she sees things, his/her feelings about a particular behavior (Fishbein \& Ajzen, 1975). Attitudes towards advertising on social networks may turn into an intention to see the ad or not, depending on the relevance of advertising on social networks; trust in social networks and trust in brands advertised on social networks.

In the context of social networks specifically, trust is understood as the belief or expectation of the trusted partner and/or the willingness to trust a partner in a number of different aspects (Grabner-Kräuter, 2009). Thus, our second hypothesis is put forward as follows:

Hypothesis 2: Attitudes towards social network advertising are positively associated with the intention to see ads on the social network.

\section{Subjective standards for viewing ads on social networks}

Subjective standard refers to the perceived social pressure of an individual to perform or not perform a behavior (Ajzen, 1991). Inside social networks subjective norms can belong to individuals or important groups in an individual's life such as friends and family members. Our third hypothesis is put forward as follows: 


\section{FACTORS AFFECTING ADS VIEWS ON SOCIAL}

Hypothesis 3: The subjective standard of viewing ads on social networks is positively associated with the intention to see ads on social networks.

Perceived behavioral control on social media advertising

Perceived behavioral control refers to the ease or difficulty of performing a specific behavior under consideration (Ajzen, 1991). Thus, our fourth and last hypothesis is formulated as follows:

Hypothesis 4: The ability to control perceived behavior of viewing ads on social networks is positively associated with the intention to view ads on social networks in case of consumers in Ho Chi Minh City.

\section{Control variables}

To enhance the reliability of the test results, the author added a number of other control variables that appear in the previous studies and that may affect the intention to see ads on social media and the behavior of viewing ads on social networks, including social networks engines such as information engines on social networks, and entertainment engines on social networks. Demographic variables were also included.

\section{Methodology}

\section{Qualitative research}

Interviews about viewing ads on social networks with open-ended questions were carried out to collect the initial data to identify the factors that influence the intent to view advertising on social networks and the behavior while viewing ads on social networks.

Group discussion (30 people with good knowledge on the researched issues) and direct interviews with behavior management experts have been carried out. In-depth semistructured interviews were also carried out to clarify the qualitative research results.

\section{Quantitative research}

Quantitative research has been aimed to determine the level of factors affecting the intentions of viewing advertising on social networks and the behavior while viewing ads on social networks. Survey methods, namely, distribution of questionnaires, have been used to collect the initial data from consumers who have experience with using social networks in Ho Chi Minh City.

\section{Data analysis}

Reliability and validity are determined through calculation of Cronbach alpha coefficients using step-by-step analysis, maximizing the reliability of the scale at 0.70 .

Cronbach coefficient alpha is accepted (as it is exceeding 0.7); thus, the measuring instruments are quite reliable. This study uses the exploratory factor analysis (EFA) and the confirmatory factor analysis (CFA) along with structural equation models (SEM) to test the hypotheses outlined above. SEM model is clear and testable, so the intention model for social advertising and the behavior of viewing social ads can be analyzed, aggregated. Therefore, it is possible to study the effects in question, whether direct, indirect or both. 


\section{Description of the survey sample}

A sample of 317 consumers was selected for the survey, using a random sampling method. The respondents have completed the questions. Only valid samples have been analyzed.

\section{Confirmatory factor analysis (CFA)}

The correlation coefficient between the components with accompanying standard deviation (Tab. 2) shows that these coefficients are less than 1 (with statistical significance). Therefore, the components are as follows: Attitudes towards ads on social networks (ATSN); Subjective standards of seeing ads on social networks (SSSN); The ability to control the perceived behavior of viewing ads on social networks (ACPSN); Intention of viewing ads on social networks (ISSN); Behavior of viewing ads on social networks (BSSN).

Table 2 - Results of testing the components

(Source: authors' calculations)

\begin{tabular}{|l|l|l|c|c|c|c|}
\hline \multicolumn{2}{|c|}{ Correlation } & Estimate & S.E. & C.R. & P \\
\hline ATSN & $<-->$ & SSSN & .092 & .028 & 3.336 & $* * *$ \\
\hline ATSN & $<-->$ & ISSN & .104 & .020 & 5.230 & $* * *$ \\
\hline ATSN & $<-->$ & ACPSN & .056 & .018 & 3.184 & .001 \\
\hline ATSN & $<-->$ & BSSN & .066 & .023 & 2.849 & .004 \\
\hline SSSN & $<-->$ & ISSN & .124 & .029 & 4.204 & $* * *$ \\
\hline SSSN & $<-->$ & ACPSN & .107 & .028 & 3.770 & $* * *$ \\
\hline ISSN & $<-->$ & ACPSN & .035 & .018 & 1.998 & .046 \\
\hline ISSN & $<-->$ & BSSN & .094 & .025 & 3.795 & $* * *$ \\
\hline
\end{tabular}

The linear structural analysis shows that the model's chi-squared statistics is 227.061 with 122 degrees of freedom and the value of $\mathrm{P}=0000$. Chi-squared relative degree of freedom according to $\mathrm{Cmin} / \mathrm{df}$ was $1.861(<2)$. Other indicators demonstrated the following results: $\mathrm{TLI}=0.932(>0.9), \mathrm{GFI}=0.937(>0.9), \mathrm{CFI}=0.950(>0.9)$ and $\mathrm{RMSEA}=0.052$ $(<0.08)$. Therefore, this model fits the data collected. This also allows us to draw individual judgments about the direction of the observed variables. As for the values' convergence, the standardized weights of the scales are $>0.5$ with the statistical significance being $\mathrm{P}<0.05$, so the scale achieved the convergence value. 


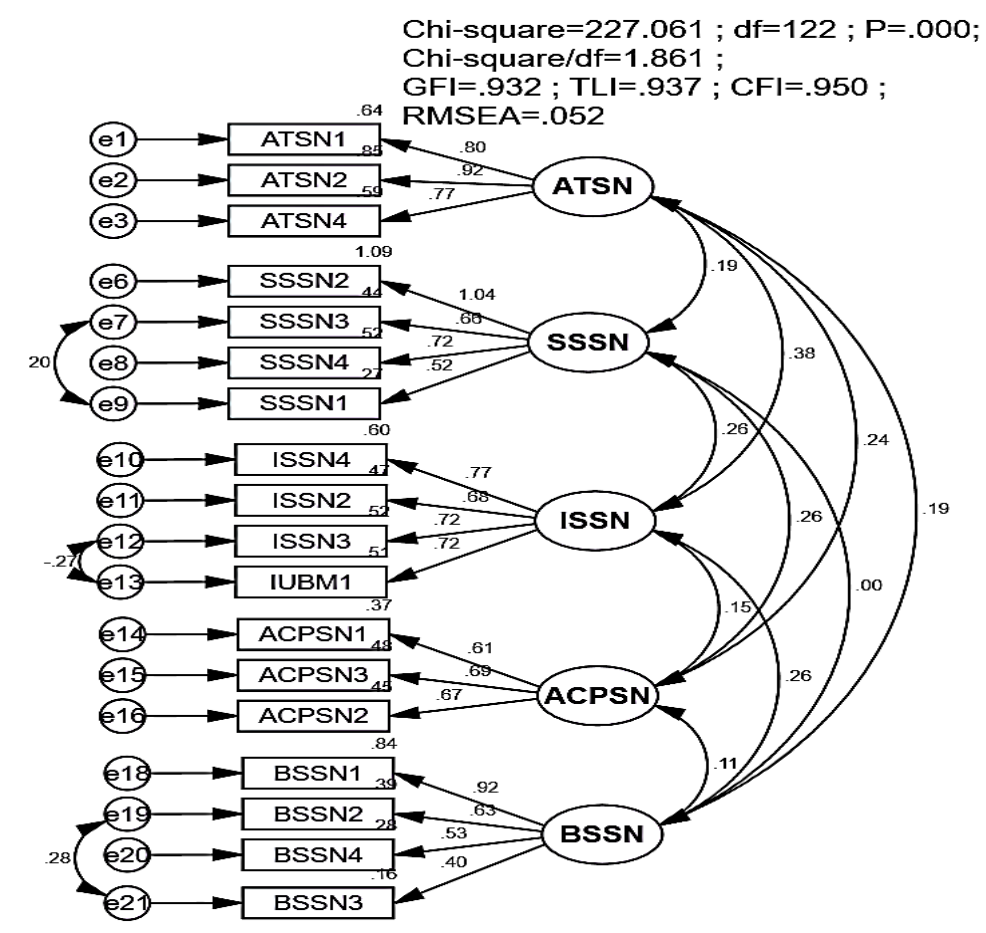

Figure 1 - Results of the CFA scale

(Source: authors' own construction)

Our model has achieved compatibility with the data already collected. The factors in question include: Attitudes towards ads on social networks (ATSN) $(\mathrm{ES}=0.273 ; \mathrm{P}=0.012$ ); Subjective standards while seeing ads on social networks (SSSN) $(\mathrm{ES}=0.481 ; \mathrm{P}=0.000)$, The Ability to control the perceived behavior of viewing ads on social networks (ACPSN) $(\mathrm{ES}=0.188 ; \mathrm{P}=0.022)$; The intention to see ads on social networks (ISSN) $(\mathrm{ES}=0.188 ; \mathrm{P}$ $=0.022)$ and the Behavior of viewing ads on social networks $(\mathrm{BSSN})(\mathrm{ES}=0.125 ; \mathrm{P}=$ 0.000). They all had the $\mathrm{P}$ values $<0.05$ and the estimated values are normalized.

\section{Testing the reliability of estimates by means of bootstrap method}

Bootstrap method is often used to test the model estimates. In our case, the model has the pattern repeat of $\mathrm{N}=1000$. The estimation results from 1000 samples are averaged together with the deviations and are presented in Tab. 5. CR has a very small absolute value, therefore, it can be stated that the deviation is very small, while not statistically significant at the $95 \%$ confidence level. Thus, we can conclude that the model estimates can be trusted. 


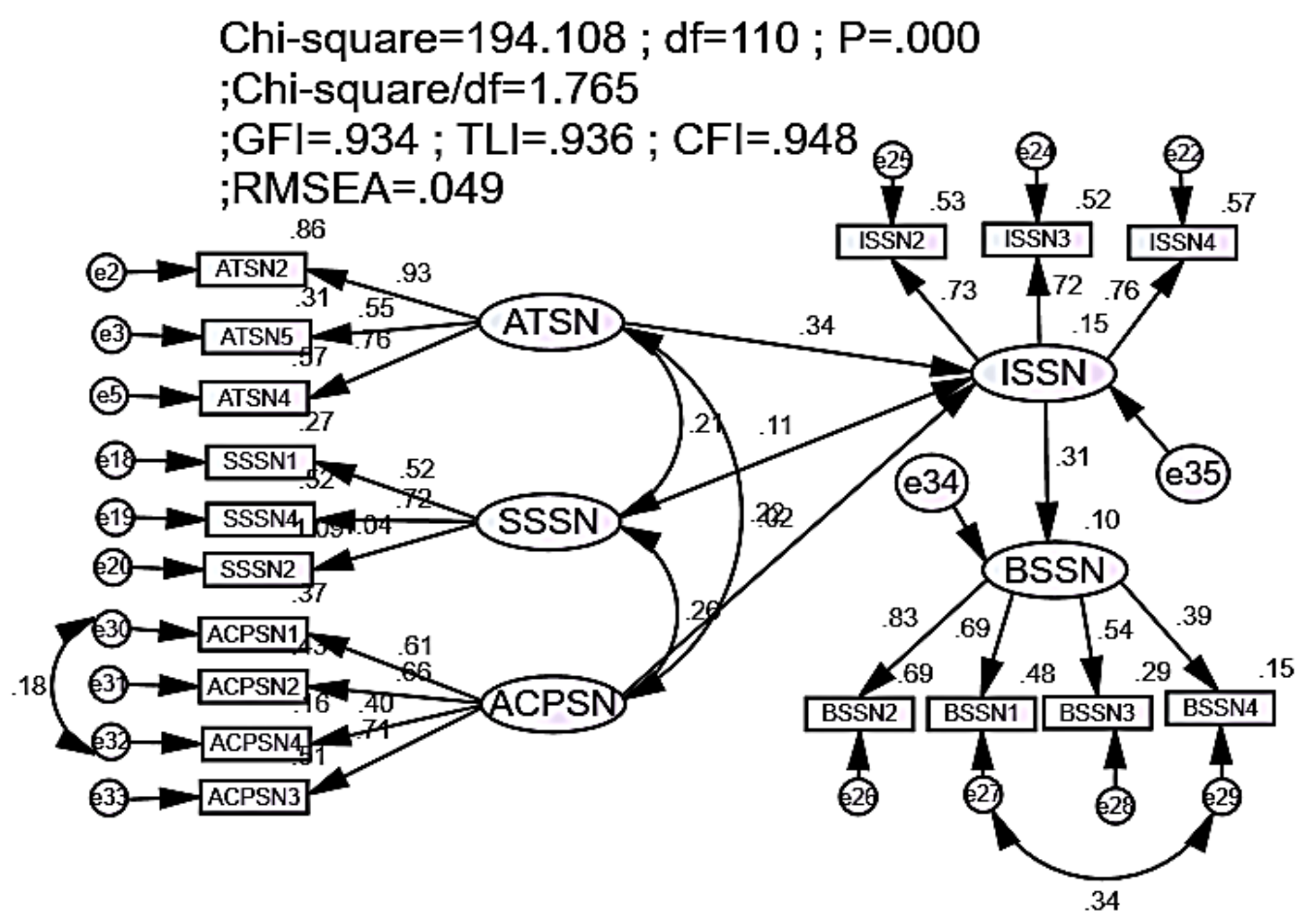

Figure 2 - SEM Results

(Source: authors' own construction)

Table 4 - Causal relationship between the factors

(Source: authors' own calculations)

\begin{tabular}{|l|c|c|c|c|c|c|c|}
\hline \multicolumn{3}{|c|}{ Relation } & Estimate & S.E. & C.R. & P & Label \\
\hline ISSN & $<---$ & ATSN & .297 & .064 & 4.666 & $* * *$ & Yes \\
\hline ISSN & $<---$ & ACPSN & .024 & .087 & .275 & .004 & Yes \\
\hline ISSN & $<---$ & SSSN & .124 & .067 & 1.847 & .005 & Yes \\
\hline BSSN & $<---$ & ISSN & .373 & .087 & 4.275 & $* * *$ & Yes \\
\hline
\end{tabular}

All the model estimates have a positive relationship with the behavior of viewing ads on social networks (BSSN). Therefore, all of our hypotheses are accepted.

Table 5 - Results estimated by bootstrap with $\mathrm{N}=1000$

(Source: authors' own calculations)

\begin{tabular}{|l|c|l|c|c|c|c|c|c|c|}
\hline \multicolumn{9}{|c|}{ Estimated Normal } & \multicolumn{4}{|c|}{ Estimate Bootstrap N=1000 } \\
\hline \multicolumn{2}{|l|}{ Parameter } & Estimate & SE & $\begin{array}{c}\text { SE- } \\
\text { SE }\end{array}$ & Mean & Bias & $\begin{array}{c}\text { SE- } \\
\text { Bias }\end{array}$ & CR \\
\hline ISSN & $<--$ & ATSN & 0.297 & 0.076 & 0.002 & 0.293 & -0.004 & 0.002 & -2.0 \\
\hline ISSN & $<---$ & ACPSN & 0.240 & 0.128 & 0.003 & 0.042 & -0.018 & 0.004 & -4.5 \\
\hline ISSN & $<---$ & SSSN & 0.124 & 0.082 & 0.002 & 0.127 & 0.003 & 0.003 & 1.0 \\
\hline BSSN & $<---$ & ISSN & 0.373 & 0.099 & 0.002 & 0.368 & -0.005 & 0.003 & -1.7 \\
\hline
\end{tabular}




\section{FACTORS AFFECTING ADS VIEWS ON SOCIAL}

\section{Results, discussion and concluding remarks}

Advertising on social networks has emerged as a new form of interactivity and social advertising. It is very different from traditional advertising since advertising on social networks provides customers with active control in the course of ads' viewing. With the constantly increasing number of Internet users and social networks members in the world in general and in Ho Chi Minh City in particular, this context is creating favorable conditions for the development of advertising on social networks.

Therefore, evaluating the factors affecting the behavior of people viewing ads on social networks from the perspective of the basic theory of consumer behavior brings significant contributions, both theoretically and practically. This study has used planned behavioral theory to study the behavior of people viewing ads on social networks in Ho Chi Minh City. More specifically, this study assesses the factors that influence the behavior of social network users (Facebook case study, 2017) in Ho Chi Minh City, Vietnam.

In a rather similar study on social networks, with the sample of university students, Muk (2013) also concluded that the intention to join the brand pages positively influences the intention of purchasing goods on the websites of same brands. Furthermore, other previous studies have also shown that the attitude to advertising positively influences the intention to perform certain behavior in relation to ads. ). Our research has also found similar results, namely, the attitude towards advertising on social networks positively affects the intention to see ads on social networks.

Our research results also show that subjective standards in advertising on social networks and the ability to control the perceived behavior of viewing ads on social networks have a positive influence on the intention to see ads on social networks.

However, this relationship is not strongly supported by the obtained research data. At the same time, previous studies have found a positive effect of the subjective norms and perceived behavioral control on the intention to perform a certain behavior in relation to ads seen on social networks (Lin et al., 2015).

This group of authors has concluded that the users of social networks (students in their sample) do not see advertising on social networks simply because that is not their purpose. Their purpose on social networks (namely, Facebook) is reaching out to other types of content, such as profiles of friends, new photos and so on. This is also true for the students in Ho Chi Minh City, as they demonstrate exactly the same behavior.

\section{Suggestions for further research}

The main drawback of our study is that the sample is limited to HCMC only. Therefore, additional studies are needed in other localities in Vietnam.

Determining the key factors behind the intention to see advertising on social networks and the behavior while viewing ads on social networks could also involve a much larger sample in other localities.

Carrying out a larger study involving samples in other localities could confirm the results of our study. It would be also curious to see whether the measures developed here are reliable and statistically valid in a different context: other education levels, other cities and countries. 


\section{References:}

Ajzen, I., \& Fishbein, M. (1980). Understanding attitudes and predicting social behavior. Englewood Cliffs, NJ: Prentice Hall.

Ajzen, I. (1991). The theory of planned behavior. Organizational Behavior and Human Decision Processes, 50(2), 179-211.

Ajzen, I. \& Driver, B. L. (1992). Application of the theory of planned behavior to leisure choice. Journal of leisure research, 24(3), 207.

Baker, R.K., \& White, K.M. (2010). Predicting adolescents' use of social networking sites from an extended theory of planned behaviour perspective. Computers in Human Behavior, 26(6), 1591-1597.

Chang, C. C. \& Chang, P. C. (2010). A Study on Taiwan Consumers' Adoption of Online Financial Service. Asia Pacific Management Review, 18.

Chin, C. Y., Lu, H. P. \& Wu, C. M. (2015). Facebook Users' Motivation for Clicking the "Like" Button, Social Behavior and Personality: an international journal, 43(4), 579-592.

Cimigo (2015). Online Mobile and Social Networks in Vietnam. Ho Chi Minh city.

Davis, F. (1993). User acceptance of information technology: system characteristics, user perceptions and behavioral impacts. International Journal of Man-Machine Studies, 38(3), 475-487.

Grabner-Kräuter, S. (2009). Web 2.0 social networks: the role of trust. Journal of business ethics, 90(4), 505-522.

Facebook Q2 2017 Earnings. Available at: https://investor.fb.com/investor-events/eventdetails/2017/Facebook-Q2-2017-Earnings/default.aspx

Hsu, C.L., Chang, C.Y. \& Yansritakul, C. (2017). Exploring purchase intention of green skincare products using the theory of planned behavior: Testing the moderating effects of country of origin and price sensitivity. Journal of Retailing and Consumer Services, 34, 145-152.

Lin, F.T., Wu, H.Y. \& Tran, T. N. N. (2015). Internet banking adoption in a developing country: an empirical study in Vietnam, Information Systems and e-Business Management, 13(2), 267287.

Lin, C. \& Kim, T. (2016). Predicting user response to sponsored advertising on social media via the technology acceptance model. Computers in Human Behavior, 64, 710-718.

Soares, A.M. \& Pinho, J.C. (2014). Advertising in online social networks: the role of perceived enjoyment and social influence. Marketing, 8(3), 245-263.

Paper submitted

Paper accepted for publishing

Paper published online
21 June 2020

06 September 2020

30 September 2020 